\title{
Paediatric illness in Hong Kong and Britain
}

\author{
D P Davies
}

The territory of Hong Kong (area $1071 \mathrm{sq} \mathrm{km}$ ), is made up of Hong Kong island, the Kowloon peninsula and the New Territories, the latter comprising mainland and over two hundred islands. Huge urban connurbations (many built on new land claimed from the sea and previous agricultural areas) have sprung up as presssures have grown to accommodate an ever burgeoning population that has expanded from 0.5 million in 1945 to nearly six million in $\mathbf{1 9 9 0 .}$ Enormous social and economic changes have also taken place as Hong Kong has emerged as one of Asia's most rapidly developing newly industrialised regions. A total of $98 \%$ of its people are Chinese, mostly from the southern provinces of China.

Improvements in childhood mortality are a revealing marker of these changes. In 1956 infant mortality was $60.9 / 1000$ and in 1989 it was $6 \cdot 9 / 1000 .^{1}$ Perinatal and neonatal mortalities in 1989 were $7 \cdot 6 / 1000$ and $4 \cdot 8 / 1000$ respectively and for children under 5 years was $8 \cdot 2 / 1000$. $^{1}$ These impressive improvements have been achieved despite periodic influxes of huge numbers of people from mainland China caused by various social upheavals in that country, migrations that would have dealt a crippling blow to the health and social services of most nations. The sorry plight of children in Hong Kong as little as a generation ago was vividly described by Professor Elaine Field and Dr Flora Baber in their classic monograph Growing up in Hong Kong where they describe the appalling living conditions of thousands of children in the $1960 \mathrm{~s}$, their often meagre nutritional state, and their affliction by widespread scourges of infections and infectious diseases. ${ }^{2}$ But how times have changed. Living conditions, through remarkable economic achievements, have improved beyond recognition. An outstanding Maternal and Child Health Service has (though still too often unappreciated) contributed so much to improve the physical well being of mothers during pregnancy, the safety of childbirth and the health of children through immunisation, physical and developmental surveillance, and general primary health care. The secular increase in physical size of Hong Kong children over the past 20 or so years of record keeping is further testament to these improvements. ${ }^{34}$ Hospital facilities for sick children, including services for the newborn, have also greatly improved and there has emerged a progressively higher overall standard of paediatric care both inside and outside hospital, helped significantly by expansions in postgraduate education and professional training programmes.
In $1982 \mathrm{I}$ arrived to spend what was to be seven years in Hong Kong. I had presumed that in a part of the world where the ravages of poverty, malnutrition, and infectious diseases belonged largely to the past, the clinical problems in children would be not that dissimilar from those in Britain, except for some obvious genetic disorders. But in quite a short time I was to discover many intriguing and unexpected variations in morbidity that reflected genetic influences and the impact of lifestyle and socioeconomic conditions on the growing child. Returned now to paediatric practice in Britain these variations in morbidity have become especially vivid. In this paper I have chosen to reflect on those conditions with particularly striking variations or that hold a certain personal intrigue for me.

\section{Genetic disorders}

The genetic disorder mostly frequently found in Hong Kong is glucose-6-phosphate dehydrogenase (G6PD) deficiency: $4 \cdot 4 \%$ of males and $0 \cdot 4 \%$ of females have been estimated to be affected. ${ }^{5}$ Not so long ago this disorder was a dreadful scourge that made a big contribution to death in the newborn period and, in the long term, to severe neurodevelopmental disability from kernicterus. In 1971 cord blood screening was introduced into a couple of hospitals and then in 1984 G6PD screening, using a quantitative assay of the enzyme activity on cord blood, was introduced throughout the territory under the direction of the Clinical Genetic Service of the then Medical and Health Department. Now, mothers and fathers of all diagnosed babies are counselled and given written information to help them understand the disorder. Admission of children to paediatric wards with haemolytic crises is now a rarity.

Thalassaemic syndromes are the most common autosomal recessive conditions among the southern Chinese. $\alpha$-Thalassaemia is still an importance cause of stillbirth and each year approximately 25 infants are born with $\beta$ thalassaemia major. The $\beta$-thalassaemia trait, prevalence about $2.5 \%$, accounts for many children having an incidental finding of a haemoglobin concentration below $110 \mathrm{~g} / \mathrm{l}$, but is rarely symptomatic and does not require treatment. ${ }^{6}$

Of genetic disorders not seen in Hong Kong compared with Britain phenylketonuria and cystic fibrosis are those most conspicuously absent. The story of phenylketonuria is especially intriguing. A study in the early 1970s of about 18000 newborn babies screened in the new

\section{Formerly Foundation Professor of Paediatrics, Hong Kong. \\ Health, \\ College of Medicine Cardiff CF4 4XN \\ Correspondence to:}


born period did not turn up any cases of phenylketonuria (Dr Henrietta Ip, unpublished data), seeming to confirm local paediatric claims that phenylketonuria is not found in Hong Kong. A contrary opinion, however, emanates from parts of mainland China, especially Shanghai, Beijing, and Guangzhou, where phenylketonuria has apparently been diagnosed leading to neonatal screening programmes being introduced. One study from the First Affiliated Hospital of Beijing Medical University of 198230 newborns screened by Guthrie's bacterial inhibition assay described an overall incidence of $1 / 16500$, rates similar to those found in white populations. ${ }^{7}$ I did, however, meet some scepticism over these findings in Hong Kong where phenylketonuria is not included in the neonatal screening programme, newborn screening being confined to G6PD deficiency and congenital hypothyroidism (with an incidence similar to that reported in white and other Asiatic populations of about one in $3500){ }^{8}$ I did not come across any child in the many schools and institutions for the mentally handicapped whom I could recall with hair fairer than usual and anything other than dark brown eyes, claims that have been made in some parts of China to support the occurrence of phenylketonuria.

It is intriguing how cystic fibrosis appears also not to have been described in the Chinese as it has been reported in Japan. ${ }^{9}$ With the recent cloning and sequencing of the gene responsible for cystic fibrosis the reason for the absence of this disease might soon be explained. Could it be that there is an abnormal mutation of the gene in the Chinese but not the one that results in the characteristic phenotype?

\section{Conditions determined before birth}

Preaxial polydactyly is much more common in Hong Kong. ${ }^{10}$ The spectrum of congenital heart disease is also slightly different with univentricular heart and severe right ventricular outflow obstruction in the newborn more common and left heart abnormalities-aortic stenosis, hypoplastic left heart, aortic coarctation-less common than in white populations. ${ }^{11} 12$ Remarkable in its virtual absence is spina bifida (anencephaly does occur but usually as part of syndromes of multiple congenital anomalies). A study from Tsan Yuk Hospital (University of Hong Kong) of the incidence of neural tube defects among all deliveries in 1961-80 (123 491 births) showed incidences of anencephaly, spina bifida, and encephalocele of $0.83,0.12$, and 0.06 per 1000 births respectively. ${ }^{13}$ Comparable incidences of spina bifida in the UK were then $1 \cdot 5-4 \cdot 1 / 1000$. Between 1984 and 1990 in the Prince of Wales Hospital* (about 30000 births) there were 15 cases of anencephaly, two of encephalocele,

${ }^{*}$ Frequent reference is made in this article to paediatric experiences in the Prince of Wales Hospital from the time of its opening in 1984 to when I left Hong Kong in 1989. This large, regional government hospital of 1428 beds is in Shatin, a huge new urban area in the New Territories and linked to north Kowloon by road and rail. The hospital accommodates the new clinical faculty of medicine of the Chinese University of Hong Kong. Its department of paediatrics with 218 medical beds (including neonatal cots) offers inpatient and outpatient services for a population now of about 1.5 million people, about $25 \%$ under 16 years of age. three of meningomyelocele (all in south Asian babies), and two of meningocele (Dr T F Fok, personal communication). The southern Chinese diet typically is rich in green vegetables, fresh fruit and rice, thereby providing a substantial amount of folic acid. Methods of cooking vegetables (rapid stir frying or by brief steaming) would be expected to preserve folic acid content better than western cooking practices where vegetables are often overcooked in boiling water. Apparently in north China spina bifida is as common as it used to be in many western countries (Professor Michael Laurence, personal communication). In these regions diet is influenced by season and fresh vegetables are scarce for much of the year. Some Chinese medical opinion has linked this higher incidence of spina bifida with a much lower folic acid intake ( $\mathrm{H}$ Ye, Symposium on Paediatrics in China and Africa, Royal Society of Medicine, London 1986). All this does more than provide a hint that the southern Chinese could be protected by their diet from abnormal neural tube embryogenesis, supporting the currently held view that folic acid sufficiency is needed to prevent the expression of genetic predisposition to neural tube defects.

Later gestation gave the impression of providing further protection for the fetus. Intrauterine growth retardation is much less common, the thin scraggy, 'small for dates' baby being an unusual sight. The ratio of midarm circumference to occipitofrontal circumference, an index of late gestation growth retardation, is significantly higher than in Asian, white, and black neonates in London. ${ }^{14}$ There is also a lower incidence of very low birth weight in Hong Kong: Lau and his colleagues in 1984 described an incidence of infants weighing $<1500 \mathrm{~g}$ at birth of $6 \cdot 9 / 1000,{ }^{15}$ considerably lower than the $14 \cdot 4 / 1000$ described over the same period in England and Wales. But such low incidences are not peculiar to Hong Kong Chinese, being reported also in Shanghai, ${ }^{16}$ and in Chinese populations in Australia. ${ }^{17}$

I suggest these more favourable intrauterine conditions are related to social factors and less maternal hypertensive disease. Teenage pregnancies are still uncommon and smoking and alcohol consumption during pregnancy very unusual. Diet in pregnancy is excellent and antenatal care in the maternal and child health clinics and hospital is very strictly supervised and full advantage is taken by most pregnant mothers. Hypertension in pregnancy is also less common in the Chinese. ${ }^{17} 18$ Since the early 1960s when mortality data began officially to be gathered, perinatal and neontal mortalities in Hong Kong have been consistently lower than in Britain. In 1965, a time when environmental conditions in Hong Kong were extremely harsh for so many of its people, perinatal mortality was $23 / 1000$ compared with about $31 / 1000$ in Britain, ${ }^{19}$ further supporting my contention that some inherent protection is conferred upon the Chinese baby before birth.

\section{Problems in the newborn}

There is a very low incidence of congenital dislocation of the hip, at least 10 times less 
common than in white babies. ${ }^{20}$ One explanation from recent ultrasound studies is that acetabular morphology of the hip joint in Chinese babies might be more favourable, causing less potential instability. ${ }^{21}$ The most common clinical problem in the newborn is neonatal jaundice. Babies in Hong Kong are born in hospital or in one of 47 maternal and child health centres scattered throughout the territory. Altogether $50-70 \%$ of normal term infants in Hong Kong have a serum bilirubin concentration $>171 \mathrm{mmol} / \mathrm{l}^{22}$ Reasons for such a high incidence of jaundice, that I used to consider of the 'exaggerated' physiological type, an imbalance between production and excretion of bilirubin, is unknown. In 1984 a study from Singapore where jaundice among Chinese babies is also very common, showed a significant association between raised cord blood $\alpha$ fetoprotein and subsequent jaundice in full term normal babies, inferring an immaturity of hepatic enzyme conjugating mechanisms. ${ }^{23} \mathrm{~A}$ study in Hong Kong in 1984 suggested that a slightly increased rate of haemolysis, as measured by carbon monoxide excretion, could be contributory. ${ }^{24}$ Another view has been that jaundice could be associated with mothers consuming certain herbal medicines during pregnancy, a tradition still popular in Hong Kong where many of these herbs are held to have beneficial effects on the process of childbirth. ${ }^{22}$ In times past newborn babies were also often given herbs by their mothers to help rid them of 'placental toxins': this practice, though much less common, still prevails, especially in the older parts of Hong Kong. In vitro studies have shown that a very popular herb, chuen-lin, can displace bilirubin from its albumin binding sites, ${ }^{22}$ but which of the $\mathbf{3 0}$ or so ingredients is the active principle is not known. In a 1985 study from Tsan Yuk Hospital, 54\% of about 10600 mothers admitted to multiple herb consumption during pregnancy. ${ }^{25}$ But contrary to other reports, and further complicating the issue, there was no significant association between maternal herb consumption during pregnancy and the extent of neonatal hyperbilirubinaemia: neither were G6PD deficient babies more severely jaundiced as a consequence of herb consumption by the mother. The intriguing association between herbs and neonatal jaundice has yet to be resolved.

But no longer is jaundice the devastating scourge it used to be. In 1971 in the University Paediatric Unit, Queen Mary Hospital, $8 \cdot 7 \%$ of term infants who developed neonatal jaundice developed kernicterus. ${ }^{26}$ Phototherapy, introduced about 20 years ago, has radically changed the face of jaundice with exchange transfusions now rarely needed. It is held also that somehow socioeconomic improvement has contributed significantly to this dramatic decline in severe jaundice (Professor C Y Yeung, personal communication). Neonatal jaundice persists not as a worrying medical problem but more of a social irritation causing separation of baby from mother in the early weeks after delivery with all its inconveniences, high bed occupancy in the neonatal nurseries, and a huge primary care burden for doctors and nurses working in the territory's many maternal and child health clinics. ${ }^{27}$

I cannot leave the newborn period without mentioning the tremendous achievement in the 1980s of the interruption of perinatal transmission of the hepatitis B virus (HBV) at birth by early vaccination and passive immunisation. There is an appalling toll in South East Asia from the HBV carrier state with hepatocellular carcinoma, hepatic cirrhosis, and carcinoma of the stomach, which are the causes of so much premature death in middle life. Many countries in Asia have now confirmed the perinatal period as the most important time for transmitting $\mathrm{HBV}$, resulting in carrier status. In Hong Kong all pregnant women are checked for $\mathrm{HBV}$ antigen status during antenatal visits. Babies of carrier mothers are given hepatitis B immunoglobulin together with a first dose of vaccine at birth followed by two further doses of vaccine at 1 and 4 months (a routine now also given to all babies of non-carrier mothers). Almost at a stroke the devastation caused by the carrier state one generation from now will have been virtually eliminated.

\section{Problems in infancy and childhood}

With childhood mortality rates in the 1980s ranked alongside the best in western countries it was a surprise to me to discover when first I arrived in Hong Kong that substantial local opinion held that undernutrition, especially of energy, calcium, vitamin $\mathrm{D}$, and iron, was a continuing problem. ${ }^{28} \mathrm{My}$ immediate impression was that the children looked a little smaller than those in Britain but they did not give any impression of being undernourished. A five year longitudinal study in our department of growth and nutrition in babies born in the urban area of Shatin showed that between 6 and 18 months there were certainly downward deviations in weight gain, and height and head circumference growth viewed against the National Center for Health Statistics (NCHS) reference curves. ${ }^{29} 30$ Skinfold thickness growth also showed much less adiposity than in white infants. ${ }^{31}$ Yet intakes of major nutrients were all well within recommended dietary recommendations. ${ }^{29} 3233$ One fascinating feeding practice was the regular use by mothers of compound herb preparations when reconstituting milk formula, ${ }^{34}$ a practice believed to stimulate the baby's appetite, enhance absorption of nutrients from the gastrointestinal tract, and help eliminate excess endogenous heat.

These very distinctive growth profiles in well nourished children, and which are also found in children in many other healthy Asiatic populations, ${ }^{35}$ made us question the advisability of using the NCHS curves as a suitable reference for the southern Chinese. We were concerned that reluctance to recognise adequate nutritional status could lead all too easily to overfeeding and a shift away from the excellent Cantonese diet, nutritionally so well balanced with its low intake of saturated fat $(30 \%$ of the total energy content ${ }^{36}$ compared with approximately $50 \%$ in the diet of British children ${ }^{37}$ ) and refined carbohydrates and high fibre and protein. But 
remarkably few were breast fed. Of about $25 \%$ put to the breast at birth in our study only 8,6 , and $2 \%$ were still breast feeding at 2,4 , and 6 months respectively. ${ }^{30}$ Very low rates of breast feeding are widespread throughout Hong Kong. This is due chiefly to misconceptions held by mothers over the value of breast feeding, the ready availability of approved milk formula, the need and desire to return to work soon after delivery, short maternity leave, lack of privacy, and an urgent life style. This is also the case in other newly industrialised countries of South East Asia. The economically rich Orient is neglecting breast feeding, but to what future cost?

Gastroenteritis, due chiefly to rotavirus, was common, accounting for about $14 \%$ of all paediatric admissions to the Prince of Wales Hospital in the mid 1980s. ${ }^{38}$ But most of these children were admitted for medically trivial reasons: gastroenteritis is no longer a serious medical problem in Hong Kong. Rarely were babies seriously dehydrated on admission to hospital. Because of a higher incidence of genetically determined deficiency of lactase in the Chinese secondary lactose intolerance might be expected frequently to complicate gastroenteritis: surprisingly it was rare, no more common than in this country. Far more frequent were iatrogenic complications of the treatment of gastroenteritis by outside practitioners: paralytic ileus and electrolyte disturbances from treatment with antimotility drugs were not infrequently found in children admitted to hospital. Pyloric stenosis was very uncommon. During the 1970s and 1980s the incidence in Britain was approximately $5 / 1000 .{ }^{39}$ In $1986-91$ there were only 14 cases seen at the Prince of Wales Hospital (approximately 0.27/1000; Dr K Liu, personal communication). Coeliac disease does not occur in the southern Chinese (although I have been told of some evidence from north China, where wheat is consumed more than in the predominantly rice consuming south, that this disorder is known there). Failure to thrive was not a common hospital problem: adverse social factors at home and poor parenting skills were not the associated risk factors they are so often found to be here, an example of the protection afforded to the young infant by support within the family that is still a strong feature of Hong Kong life despite its high degree of urbanisation. In older children the chronic bowel inflammatory diseases, ulcerative colitis and Crohn's disease, are non-existent, as indeed they are in adults. Hong Kong is far from a Garden of Eden for the paediatric gastroenterologist!

I was very surprised when I went to Hong Kong to discover how little aware were paediatricians there about cot death (SIDS). ${ }^{40}$ But Hong Kong was not alone in being so unaware of cot death. Paediatricians in China and other South East Asian countries confirmed a similar very low incidence. (In America the incidence of cot death has also been reported as lowest in the Asians. ${ }^{41}$ ) In a prospective study between 1 December 1986 and 31 November 1987, covering 70519 births, only 21 cases of cot death were recorded in the whole of Hong
Kong, an incidence of $0 \cdot 29 / 1000 .{ }^{42}$ Comparable incidences in Britain were then about $2-4 / 1000$. To explain this much lower incidence we wondered whether the 'microenvironment' of Hong Kong infants with crowded living conditions leading to babies never being left alone (a marked contrast to the solitary sleeping habits of so many western babies) might somehow protect, perhaps through an influence on the control of breathing at a particularly vulnerable developmental stage. We wondered also, as have many others since, whether supine sleeping might also protect as traditionally Chinese babies in Hong Kong are seldom put to lie in the prone position for fear of suffocation; $44 \%$ of the index babies in our study compared with $7 \%$ of controls had this sleeping posture. ${ }^{42}$ Supine lying does not increase risks of choking as is still widely taught in Britain. I believe that protective influences exist for cot death that are linked with cultural attitudes to infant care. There is somewhere an 'ethnic-geographical' clue to help us better understand the aetiology of SIDS and it is now well overdue that we look at cot death in a more anthropological perspective.

Iron deficiency still arouses concern in Britain with reported prevalences at $12-45 \%$ in major urban areas ${ }^{43}$ and especially common in nonwhite children. Held responsible are poor weaning diets and widespread consumption of pasteurised cows' milk with its negligible amount of iron and risks of causing gastrointestinal blood loss. ${ }^{44}$ In Hong Kong, and despite concern in the recent past about dietary deficiencies of iron, calcium, and vitamin D during weaning, we were able to show virtually no iron deficiency $(<2 \%)$ at 18 months when weaning had been largely completed. ${ }^{32}$ There was also no nutritional vitamin D deficiency ${ }^{33}$ other than in some Vietnamese children and those more recently arrived from mainland China. With maternal and child health clinics recommending affordable iron and vitamin fortified formulas as breast milk substitutes well into the second year along with an excellent weaning diet and exposure to plenty of sunshine, it is not surprising that what are among the most common nutritional deficiencies in so many other parts of the world, developed and developing alike, are so infrequent in Hong Kong.

Kawasaki disease is far more common than in Britain, ${ }^{45}$ although nowhere near the high incidence of Japan. Fifty five children were diagnosed at the Prince of Wales Hospital in 1987-90 (Dr D Leung, personal communication). I was surprised to find Myasthenia gravis in young children occurring more frequently than in white children. In its early onset, mild natural course, and frequent spontaneous remissions ${ }^{46}$ it is limited mostly to fatiguability of the ocular muscles: children usually present with ptosis and ophthalmoplegia and sometimes as young as 2 years of age. There is a strong association with the histocompatibility complex HLA-DRw9, a genetically determined variant occurring more often in Chinese. ${ }^{47}$ Children presenting with extrapyramidal dyskinetic symptoms, oculogyric crises, caused by 
drugs often prescribed by general practitioners such as prochlorperazine (prescribed for upper respiratory symptoms) and metoclopramide (for vomiting) and complication of some Chinese medicinal treatments were commonly seen. ${ }^{48}$ Their prompt recognition in accident and emergency departments as a cause of bizarre acute neurological symptoms was important as intravenous diphenhydramine would rapidly reverse the symptoms.

Acute poststreptococcal glomerulonephritis is still far more common than in Britain, though rheumatic fever, the other important streptococcal related illness, is exceedingly rare. Over five years, 1984-9, only two children were diagnosed in the Prince of Wales Hospital to have rheumatic fever in contrast to 216 with acute nephritis. Of 74 children with acute nephritis admitted over an 18 month period in 1984-6 preceding streptococcal infection was as much in the skin as in the throat. ${ }^{49}$ Barely a month would go by without a child being admitted with serious upper gastrointestinal bleeding. One study from the Division of Paediatric Surgery, Queen Mary Hospital, recorded as many as 49 children admitted with upper gastrointestinal haemorrhage between 1985 and $1988 . .^{50}$ This bleeding in young children was usually attributable to multiple superficial gastric erosions and there was more than a high index of suspicion to blame aspirin and steroids contained in some medications prescribed outside hospital. Systemic lupus erythematosus is well recognised to occur more often in Chinese people ${ }^{51}$ and this was evident in Hong Kong hospital paediatric practice, girls particularly being affected. A serious multiple system disease, systemic lupus erythematosus is a common cause of end stage renal failure in Hong Kong. In contrast insulin dependent diabetes mellitus was much less common.

Child abuse and the enormous range of problems encapsulated by this diagnosis provided appreciable contrasts. The first case of child abuse in Hong Kong was officially documented in 1979 and since then its manifold physical and emotional components have increasingly become a major focus of medical and social concern. There is no systematic documentation of its incidence but there is no doubt that non-accidental physical injuries, for example bruises, burns, bites, lacerations, fractures, subdural haematoma, etc, which are problems that have been increasingly recognised in Britain over the past 30 years, are very much less common. In the Prince of Wales Hospital only 38 children were admitted in the three year period 1984-7 suffering confirmed or strongly suspected non-accidental injury, ${ }^{52}$ and I have no reason to believe that this was then anything other than an accurate reflection of the situation throughout Hong Kong. Most of the abuse was physical, and related predominantly to the discipline of older children (in our study only eight were under 5 years old), exacted chiefly for disobedience or misconduct at home. Child beating was sometimes viewed an acceptable practice. There was only one possible instance of sexual abuse. Many children in whom physical abuse was diagnosed had been born in
Hong Kong, sent to China to be brought up by relatives only to return unknown to the parents who in turn failed to cope with stresses posed by a young child rejoining the family.

An appropriate comparison to this experience in Britain is in a 1990 paper from Leeds, population of about 750000 (fewer than the one million or so population then served by the Prince of Wales Hospital), where between 1985 and 1988, 769 children with physical abuse and 949 with sexual abuse were diagnosed. ${ }^{53}$ I am not naive enough to deny the possibility that the real incidence of child abuse in Hong Kong could be more than it gave the impression of being (especially perhaps in the massive housing estates in the New Territories where many young families are now being housed, many miles away from their families in the older urban areas of Hong Kong and Kowloon). But even allowing for this possibility it was nowhere near the magnitude it is now in Britain. But why? A very large number of families live in extremely overcrowded living conditions that would not be tolerated in this country, even in the most disadvantaged council estate. Paradoxically perhaps might 'opportunities' for abuse be less? The extended family is still very strong in Hong Kong with tremendous support given by other family members to mothers and young children who are highly cherished and valued; this could be preventing abuse. There are virtually no unmarried mothers, few teenage pregnancies, and almost full employment; these are factors that could also provide an umbrella of protection.

Enuresis and encopresis, in this country often considered social and behavioural problems, were seen much less often in outpatient and maternal and child health clinics. A community study in 1987 in Shatin of 2500 children aged 3-7 attending normal kindergardens and primary schools revealed that $84 \%, 98 \%$, and virtually $100 \%$ of the children were reported by their parents to be dry at 3,6, and 7 years respectively. ${ }^{54}$ This compared then with prevalences from multiple data on children from Britain, western Europe, Australia, and North America between 1956 and 1969 of $68 \%, 84 \%$, and $89 \%$ of children at similar ages being dry at night. ${ }^{55} \mathrm{I}$ am still curious why bed wetting is such an uncommon problem there: adverse environmental factors, including unsatisfactory housing, have been quoted as unfavourable variables in militating against successful treatment of bed wetting. 56

Sporadic infectious diseases occurred and affected children were usually referred to the single Infectious Disease Unit in Princess Margaret Hospital in Kowloon. The most common communicable diseases were viral hepatitis and bacillary dysentery, resulting usually from food contamination. With impressive immunisation uptakes, rates varying from $88 \%$ to $99 \%$ in $1988-9$, outbreaks of measles and whooping cough were exceedingly rare. I cannot also recall seeing or hearing about about any child with a serious complication of pertussis immunisation. $H I V$ infection was confined to the haemophiliac population: in $1987,40 \%$ of haemophiliac children possessed 
the HIV antibody (Dr N K Leung, personal communication). Perinatally acquired HIV infection had yet to be described in Hong Kong when I was there.

One very interesting feature given the high population density of urban living in Hong Kong was the virtual absence of meningococcal meningitis. Haemophilus influenzae was the commonest cause of bacterial meningitis. Of 61 patients aged 4 days to 11 years with bacterial meningitis admitted to one of the paediatric units at Princess Margaret Hospital between 1979 and 1985 there was not one case of meningococcal meningitis (Dr N K Leung, personal communication). Our experience in the Prince of Wales Hospital mirrored this, not one case of meningococcal meningitis being diagnosed in 1984-9. Between 1986 and 1988 there were only 14 notified cases of 'cerebrospinal meningitis' and meningococcal infection in the whole of Hong Kong, adults and children combined. ${ }^{57}$ Reasons for the extremely low incidence of meningococcal disease are not known. Might it be crowded living conditions from birth produce from a very early age a protective antibody response in the whole population?

I would like finally to turn to some disorders that impressed me as having an incidence that showed no obvious differences between west and east. Acute respiratory tract infections, of upper and lower respiratory passages, were very common reasons for hospital admission. Audit of admissions to the paediatric wards of the Prince of Wales Hospital in 1984-8 showed lower respiratory tract infections accounting for $41 \%$ of admissions. ${ }^{38}$ In recent years, and in common with many other countries, there has been reported in Hong Kong an increased prevalence of asthma with many more children requiring hospital admission in recent years. ${ }^{58}$ Febrile convulsions were as common. Urinary tract infections were also much the same and presented in the usual way. Normal variant short stature was as much a problem but without the 'indulgence' of being able to treat these children with growth hormone. Neuromuscular disorders and neurodevelopmental handicap gave an impression of being no less common than in Britain, but exact statistics are not available. As paediatrician to a school of nearly 300 severely mentally handicapped children where I used to conduct weekly 'primary care' clinics and was responsible also for the continued care of the children, I did not discern any obvious difference in the range of the causes of handicap. Some of the most distressing children were orphans who at some stage had been labelled as mentally handicapped, not for any obvious physical reason but as a consequence of abandonment, lack of care and stimulation, and behavioural disturbance acquired through their own emotional conflicts during passages between orphanages and other care centres and institutions. Disturbed they might be, under achieving their potential they undoubtedly were, but mentally handicapped they were not. For as long as this label remained around their necks the solution of their problem through adoption was difficult. Over the years I was encouraged to find fewer of these so labelled and some normal kindergardens had begun to accept these children.

In recent years the problems of the chronic multiple handicapped child have become increasingly a concern in Hong Kong. For too long tucked away out of sight these children are now being recognised for what they are and for what they need. But there was still too little awareness of the multiple physical, educational, behavioural, and social problems of these children. Hopefully the much greater exposure now being given to the current generation of medical students will reap rewards in future years to improve the outlook for these children.

\section{Conclusion}

Textbooks used in Hong Kong are written by paediatricians in western countries with often little regard for geographical variations in the pattern of illness. The fascinating variations that gradually unfolded in the patterns of illness in the Chinese children of Hong Kong came therefore to have important repercussions beyond their simple biological interest. Undergraduate and postgraduate teaching had to emphasise these variations to be meaningful and relevant.

There is another relevance to paediatricians in general. The return of Hong Kong to the sovereignty of China in 1997 will lead to a continuing increase in the numbers of young Chinese families coming to live in western countries, most notable being the USA, Australia, New Zealand, Canada, and Britain. The health needs of their children need to be understood if they are to be suitably provided. I would like to think that some of my observations will help in this understanding.

I thank my many friends and professional colleagues in Hong Kong who over the years helped me gain a balanced perspective of the clinical problems of Chinese children culminating in these final impressions. If any misperceptions and inaccuracies have crept into the text I am solely to blame. For these I apologise.

1 Hong Kong Medical and Health Department. Annual report. Hong Kong: Hong Kong Medical and Health Department,

2 Field CE, Baber FM. Growing up in Hong Kong. Hong Kong: Hong Kong University Press, 1973.

3 Leung SSF, Lam TM, Lui S, et al. Height, weight and head circumference in Shatin children 3-7 years of age: further evidence for secular change. Hong Kong fournal of Paediatrics 1987;4:43-51

4 Lau SP, Fung KP. Secular trends of growth in Hong Kong children. Hong Kong fournal of Paediatrics 1987;4:33-42.

5 Chau AS, Lam STS, Ghosh A. Genetic services in Hong Kong. F Med Genet 1990;27:380-3.

6 Lam TK, So LY, Poon SH, et al. Prevalence of $\beta$ thalassaemia trait in Hong Kong children. Hong Kong fournal of Paediatrics 1989;6:119-21.

7 Liu Shen-ru, Zuo Qi-hua. Newborn screening for phenylketonuria in eleven districts. Chin Med f [Engl] 1986;99: 113-8.

8 Chan VSM, Lam STS. The Hong Kong government neonatal screening programme for congenital hypothyrodisim.
Proceedings of an international conference on mental retardation. Hong Kong, April 1991:21-2.

9 Yamashiro Y, Oguchi S, Shimizu T, et al. Neonatal mass screening of $\mathrm{CF}$ in Japan-a preliminary report. Proceedings screening of CF in Japan-a preliminary report. Proceedings
of an international conference on cystic fibrosis. Melbourne,
1988:21 (abstract G(b)4).

10 Chen JCY, Chow SK, Leung PC. Classification of 578 cases of congenital upper limb anomalies with the IFSSH system. of congenital upper limb anomalies with the IFSSH system. A 10 years

11 Lo NS, Leung P, Lau KC. Pattern of congenital heart disease in Hong Kong. Hong Kong fournal of Paediatrics 1985;2: 188-93. 
12 Sung RYT, So LY, Ng HK, et al. Echocardiography as a tool for determining the incidence of congenital heart disease in newborn babies: a pilot study in Hong Kong. Int $\mathcal{F}$ Cardiol 1991;30:43-7.

13 Ghosh A, Woo JSK, Poon IML, Ho-Kei Ma. Neural tube defects in Hong Kong Chinese. Lancet 1981;ii:468-9.

14 Davies DP, Lui S, Lo L, et al. The ratio of mid-arm circumference to occipital frontal circumference in Chinese babies: a marker of late gestation growth retardation. Early Hum Dev 1987;15:329-32.

15 Lau SP, Au-Yeung CL, Yeung BWY, et al. Major determinants of neonatal mortality in Hong Kong. Hong Kong minants of neonatal mortality in H.
fournal of Paediatrics 1984;1:22-9.

16 Chalmers I. Shanghai. Lancet 1980; 1 :137-9.

17 Beischer NA, Liang ST. A glimpse at Chinese obstetrics 1984 why do Chinese have a low incidence of prematurity? Aust NSF Obstet Gynaecol 1984;24:233-4.

18 Lyon AJ. Trends in perinatal mortality of British and Chinese infants delivered in the British Military Hospital, Hong Kong: 1976-85. Hong Kong fournal of Paediatrics 1987;4: 20-7.

19 Lau SP, Davies DP, Fung KP, et al. Perinatal and neonatal morbidity in Hong Kong: an appraisal. Bulletin of the Hong Kong Medical Association 1985;37:1342-4

20 Hoaglund FT, Kalamchi A, Poon R, et al. Congenital hip dislocation and dysplasia in southern Chinese. Int Orthop $1981 ; 4: 243-6$.

21 Chan YL, Chen JCY, Metreweli C. Sonographic evaluation of acetabular morphometry in Chinese infants-an answer to the relatively low incidence of congenital hip dislocation in the Chinese. 27th Congress of the European Society of Paediatric Radiology. Munich, 1990:388 (abstract 39).

22 Yeung CY, Lee FT, Wong HN. Effect of a popular Chinese herb on neonatal bilirubin protein binding. Biol Neonate herb on neonata

23 Tan KL, Loganath A, Roy AC, et al. Cord plasma fetoprotein values and neonatal jaundice. Pediatrics 1984;74:1065-8.

24 Lau SP, Wong KH, Fung KP, et al. Carbon monoxide production and neonatal hyperbilirubinaemia. Hong Kong fournal of Paediatrics 1985;2:93-4.

25 Fok TF, Lau SP, Hui CW. Chinese herbs in pregnancy and neonatal jaundice. Hong Kong foumal of Paediatrics 1985;2: $138-44$.

26 Yeung CY. Neonatal hyperbilirubinaemia in Chinese. Trop Geogr Med 1973;25:151-7.

27 Leung SL, Lai PYF, Davies DP. A survey of work undertaken in 1 year by a medical officer working in a maternal and child health clinic in Hong Kong: implications for training. Ann Trop Paediatr 1990;10:99-108.

$28 \mathrm{Li}$ AMC, Baber FM, Yu AMC. Infant feeding practices among Kwun Tong mothers. Fournal of the Hong Kong Medical Association 1985;37:181-4.

29 Davies DP. Nutritional problems in infancy and early childhood: a commentary on the contemporary Hong Kong scene. Hong Kong Fournal of Paediatrics 1988;5(suppl): 135-51.

30 Leung SSF. Auxological and nutritional status of Hong Kong Chinese infants: birth - two years. Hong Kong: The Chinese University of Hong Kong, 1990. (MD thesis.)

31 Davies DP, Leung SSF. Triceps and scbscapular skinfold growth from birth to 18 months in Hong Kong Chinese infants. In: Tanner JM, ed. Auxology No 88. Perspectives in the science of growth and development. Selected papers from the fifth international auxology congress, Exeter, July 1988. London: Smith-Gordon, 1989:139-42.

32 Leung SSF, Davies DP, Lui S, et al. Iron deficiency is uncommon in healthy Hong Kong infants at 18 months. f Trop Pediatr 1988;34:100-3.

33 Leung SSF, Lui S, Swaminathan P. Vitamin D status of Hong Kong Chinese infants. Acta Paediatr Scand 1989;78: 303-6.
34 Sung RYT, Lui S, Lo S, et al. Traditional Chinese infant supplementary medical foods given by mothers in Hong Kong. Early Hum Dev 1988;17:157-63.

35 Davies DP. The importance of genetic influences on growth in early childhood with particular reference to children of Asiatic origin. In: Waterlow JC, ed. Linear growth retardation in third world countries. Nestlé nutrition workshop. No 14 New York: Raven Press, 1988:75-90.

36 Leung SSF, Lui S, Davies DP. Cholesterol and diet. Arch Dis Child 1989;64:1642-3.

37 Tarlow MJ. Cholesterol and diet. Arch Dis Child 1989;64: 647-8.

38 Leung DTY, Tseng RYM, Davies DP. Setting up a clinical audit of paediatric morbidity in Hong Kong: some early experiences. Australian Paediatric fournal 1987;23:111-3.

39 Tam PKH, Chan J. Increasing incidence of hypertrophic pyloric stenosis. Arch Dis Child 1991;66:530-1.

40 Davies DP. Cot death in Hong Kong: a rare problem. Lance 1985;ii:1346-8.

41 Kelly DH, Shannon DC. Sudden infant death syndrome and near sudden infant death syndrome. A review of the literature 1964/1982. Pediatr Clin North Am 1982;29. 1241-61.

42 Lee NNY, Chan YF, Davies DP, Lau E, Yip DCP. Sudden infant death syndrome in Hong Kong: confirmation of low incidence. $B M \mathcal{F}$ 1989;298:721.

43 Grindulis H, Scott PH, Belton NR, Wharton BA. Combined deficiency of iron and vitamin D in Asian toddlers. Arch Dis Child 1986;61:843-8.

44 Mills AF. Surveillance for anaemia: risk factors in patterns of milk intake. Arch Dis Child 1990;65:428-31.

45 Wang RPS, Chow CB, Leung NK. Kawasaki disease in Hon Kong. Hong Kong fournal of Paediatrics 1986;31:34-41.

46 Chan-Lui WY, Lau TTY, Leung NK. Myasthenia gravis in Chinese children. Dev Med Child Neurol 1984;26:717-24.

47 Hawkins BR, Yu YL, Wong V, et al. Possible evidence for variant of myasthenia gravis baséd on HLA acetylcholine variant of myasthenia gravis based on HLA acetylcholine receptor

48 Sung RYT. Five children with drug induced extrapyramidal symptoms. Hong Kong Fournal of Paediatrics 1985;2 $197-200$.

49 Leung DTY, Tseng RYM, Go SH, French GL, Lam CWK. Post-streptococcal glomerulonephritis in Hong Kong. Arch Dis Child 1987;62:1075-6.

50 Tsang TR, Hhut Saing. Endoscopic diagnosis of upper gastro-intestinal bleeding in

51 Hopkinson ND. Systemic lupus erythematosus: epidemiological clues to its aetiology. Br f Hosp Med 1991;45:291-4.

2 Lau Iris KC, Davies DP. Non accidental injury to children in Hong Kong. A 3 year hospital experience. Welsh Paediatric Hournal 1991;3:10-5.

53 Hournal $1991 ; 3: 10-5$. The sexually abused battered child. Arch Dis Child 1990;65:423-7.

54 Davies DP. Bed wetting in Hong Kong Chinese children: a relatively uncommon problem. Hong Kong foumal of relatively uncommon prot

55 De Jonge GA. Epidemiology of enuresis: a survey of the literature. In: Kolvin I, Mackeith RC, Meadow SR, eds. Bladder control and enuresis. Clinics in developmental medicine. Nos 48/49. London: William Heinemann for Spastics International Medical Publications, 1973:39-46.

56 Devlin JB, O'Cathain C. Predicting treatment outcome in nocturnal enuresis. Arch Dis Child 1990;65:1158-61.

57 Hong Kong Medical and Health Department. Annual report. Hong Kong: Hong Kong Medical and Health Department, 1989.

58 Tseng RYM, Lam YM, Davies DP. Hospitalisation of childhood asthma in Hong Kong: 1976-1985. Public Health 1988;102:275-9. 